MATEC Web of Conferences 19, 01021 (2014)

DOI: $10.1051 /$ matecconf/ 20141901021

C Owned by the authors, published by EDP Sciences, 2014

\title{
Calculation methodology of fast fission factor in a thermal reactor
}

Denis V. Grishko, Arian V. Kuzmin, Dmitry Y. Malishev

National Research Tomsk Polytechnic University, 634050 Tomsk, Russia

\begin{abstract}
This article describes the coefficient of the fast fission, which is part of the formula of «four factors». Considered, to exist at the moment, two methods for calculation of the coefficient of the fast fission in uranium-water tight lattices. Also presents the results of calculations and comparative analysis of the data obtained by two techniques.
\end{abstract}

\section{Introduction}

Cross-section of fission fuel $\left({ }^{235} \mathrm{U},{ }^{239} \mathrm{Pu},{ }^{233} \mathrm{Th}\right)$ is a continuous spectrum with energy distinct from zero. It is mean, that in all reactors there are processes of fission on a heat, resonance and fast neutrons. Such elements as uranium and thorium are fissionable at specific energy (higher than boundary energy). For example, fast neutrons with energy $1.1 \mathrm{Mev}$ fission ${ }^{238} \mathrm{U}$. There is a chance that fast neutrons will cause fission. It appearance causes other fission neutrons. The coefficient of the fast fission accounts this process.

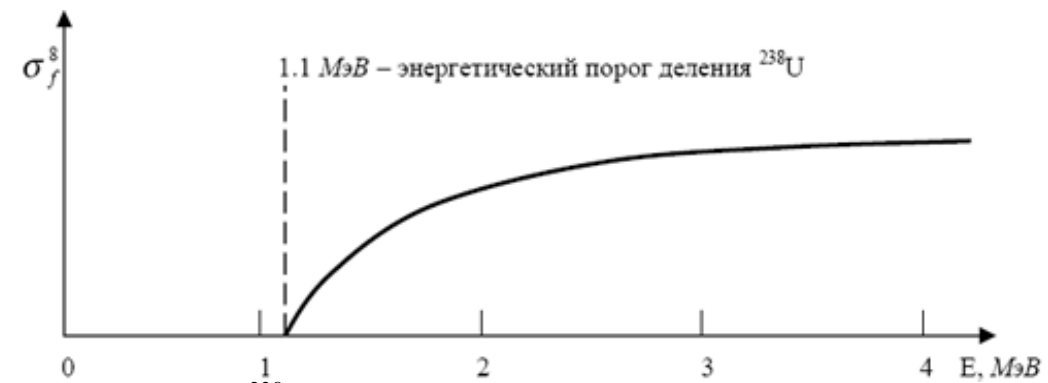

Fig. 1 characteristic curve micro-cross-fission ${ }^{238} \mathrm{U}$ of neutron energy.

\section{Problem statement}

The Monte Carlo method is an accurate method in calculating the coefficient of the fast fission. But to use it requires writing a program and use of computers. Therefore, the main problem in this situation is the ability to quickly and accurately calculate this ratio without the use of complex calculations.

\section{Mathematical model}

The coefficient of the fast fission $\mu$ is defined asa rationumber of fast neutrons generated in a nuclear reactor by all fissions to the number of the fast neutrons generated by thermal fission. American scientist Leo Szilard was first who discovered that this coefficient important for neutrons balances. This factor was used in the plutonium project first time.

Fast fission factor depends from such characteristics as: the radius of block, uranium-water ratio and fuel enrichment. It is necessary to determine the explicit dependencies and justify it. The higher radius of block the higher fast-fission factor, it is caused byincreased likelihood of a neutron collision test in the block in which it arose. The higher the uranium-water ratio the higher value $\mu$, it is caused by «cross effect». The higher concentration of ${ }^{235} \mathrm{U}$ the lower $\mu$. As already mentioned, the coefficient of the fast fission depends on the ration $\frac{V_{U O_{2}}}{V_{\mathrm{H}_{2} \mathrm{O}}}$, which determines the grid as "close" or "discharged".Lattice considered "tight" if:

$$
\bar{l}_{\text {зам }} / \lambda_{s}^{\text {зам }}<1
$$

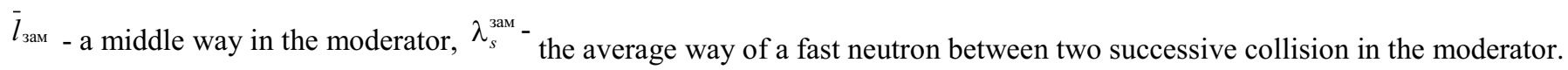

Only "tight" lattice will be used further for the research.

The problem of heterogeneous reactor calculationconsist in the neutron fluxes at each point of the core have a different meaning, and its boundaries should be considered neutron leakage from the reactor.Calculation is complicated by infeasibility of diffusion approximation in point of the core and border moderator layer too. Equivalent mesh is divided from lattice to simplify 
calculation. It is suggested neutron characteristics and size of equivalent mesh are even. That has made it possible to study only one mesh. Hereafter 0 is the index of equivalent mesh block, $1-$ is the index of moderator.
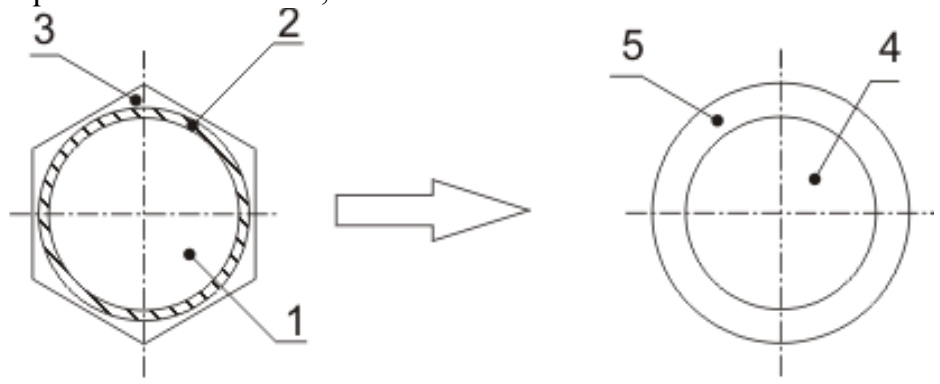

Fig. 2 transformation real lattice in equivalent mesh block.

1 - fuel, 2 - fuel element jacket, 3 - moderator, 4 -equivalent mesh block, 5 - moderator of equivalent block.

In our day there are two methods of calculating the fast fission coefficient. The first method is described in [1], which is based on a method of first collision probability.Principle of method: calculation of the probability of simple spatially distributed sources with an isotropic angular distribution of the neutrons. The probability of neutron collision, which start move in the zone $\mathrm{i}$, is:

$$
P_{i j}=\frac{\Sigma_{t j}}{V_{i}} \int_{V_{i}} d r r_{V_{j}} \frac{\exp \left(-\overline{\Sigma_{t} \cdot R_{12}}\right)}{4 \cdot \pi \cdot R_{12}^{2}} d r,
$$

$\overline{\Sigma_{t} \cdot R_{12}}$ - the total optical thickness of the motion of the neutron from point $\mathrm{r}^{\prime}$ to point $\mathrm{r} ; R_{12}=\left|r-r^{\prime}\right|-$ total cross section for the interaction of neutrons with the nucleus zone $\mathrm{j}$.

Subject to the assumptions and approximations (rational Wigner approximation) for two-region mesh there is a formula for calculation collision probability of neutrons in a block of tight lattice:

$$
Q_{00}=\frac{\bar{l}_{0} \cdot \Sigma_{x 0}}{\bar{l}_{0} \cdot \Sigma_{x 0}+a \cdot \gamma_{p}},
$$

$\bar{l}_{0}=4 V_{0} / F_{0}$ - average chord in the equivalent mesh block; $\Sigma_{x 0}=\Sigma_{a 0}+\Sigma_{R 0}-\chi \cdot v_{f}^{8} \cdot \Sigma_{f 0}^{8}$ - neutron cross-section in the block; $\chi-$ quantity of fission neutrons with energies higher than boundary energy (for $E_{\text {пор }}=0,821 \mathrm{MэB} \chi=0,752$ ); $\Sigma_{R 0}-$ slip-section of neutrons from the block (assuming that only the inelastic scattering is accompanied by a great loss of energy $\sigma_{R}=\sigma_{i n}$ ); $a-$ variable of Bell, depend of optic depth and shape of the body $(a=1.5) ; \gamma_{p}$ - shading coefficient in the lattice:

$$
\gamma_{p}=\frac{C}{1+(a-1)(1-C)},
$$

$C$ - Dankova-Ginzburg coefficient.

Value $C$ was used to account the resonance absorption of neutrons in tight lattices. There are many shrewd approximation formulas for the calculation of the coefficient of Dancova-Ginsburg, but the most widespread formula proposed by Sauer. For cylindrical blocks it appear as follows:

$$
C=1-\frac{\exp \left(-t \cdot \Sigma_{x 1} \cdot \bar{l}_{1}\right)}{1+\Sigma_{x 1} \cdot \bar{l}_{1} \cdot(1-t-\delta t)} .
$$

$\Sigma_{x 1}=\Sigma_{a 1}+\Sigma_{R 1}$ - Effective cross section of the moderator;

$t=\left(b_{p}-d_{0}\right) / \bar{l}_{1}-$ the shortest distance between the surface of the block, measured in units of $\bar{l}_{1}$;

$\delta t=\Sigma_{x 1} \cdot \bar{l}_{1} /\left(7+\beta \cdot \Sigma_{x 1} \cdot \bar{l}_{1}\right)$ - allowance Bonalumi the shape of the mesh;

$\beta$ - coefficient depending on the shape of the mesh $(\beta=17 / 3$ - for the hexagonal mesh, $\beta=17 / 8$ - for square lattice);

The formula for the calculation of the fast fission in tight lattices:

$$
\mu=1+\chi \frac{v_{f}^{8} \cdot \Sigma_{f 0}^{8}-\Sigma_{a 0}}{\Sigma_{t 0} / Q_{00}-\left(\chi \cdot v_{f}^{8} \cdot \Sigma_{f 0}^{8}+\Sigma_{s 0}\right)} .
$$

For highly enriched uranium $\left(\mathrm{C}_{5}>5 \%\right)$, formula for the calculation include the divisions of ${ }^{235} \mathrm{U}$ in the above-threshold energies:

$$
\mu_{*}=\mu \frac{\bar{v}_{f}^{-5} \cdot \bar{R}_{f \mathrm{r}}^{5}}{v_{f} \cdot \bar{R}_{f \mathrm{r}}^{5}-\bar{v}_{f} \cdot \Sigma_{f}^{5} \cdot \bar{\Phi}_{0}},
$$


$\bar{R}_{f \mathrm{r}}^{5}$ - Fission counting rate in thermal range; ${ }_{v_{f}}^{-5} \cdot \Sigma_{f}^{5} \cdot \bar{\Phi}_{0}$ - the number of neutrons produced by fission ${ }^{235} \mathrm{U}$ neutrons suprathreshold.

Another method of calculating the coefficient of the fast fission is presented in the work [2]. In this metod fast neutrons are separated into three groups, than, as in the previous method, the average cross-section is calculated for fast neutrons, which belong to the first group only.

Group 1: That portion of the fission spectrum with energies above $1.4 \mathrm{MeV}$. The fission spectrum is considered by formula:

$$
\Phi(E)=\exp (E / 0,965) \cdot \sinh \sqrt{2,29 \cdot E} .
$$

Group 2: This is a part of the fission spectrum, which located below the fission threshold ${ }^{238} \mathrm{U}$.

Group 3: Those neutrons which have been scattered out of group 1 because of elastic and non-elastic scattering. The spectrum is taken to be:

$$
\Phi(\mathrm{E})=\mathrm{E} \cdot \exp (-\mathrm{E}) ; \mathrm{E}<1,4 \text { МэВ. }
$$

Submitted function of the neutron spectrumis unnormalized Watt spectrum for promptly born neutron.

The formula for calculating the coefficient of fast fission factor for an infinite lattice:

$$
\mu_{\infty}-1=C_{1} \cdot G_{1}-C_{2} \cdot L_{2}-C_{3} \cdot L_{3},
$$

Where $C_{l}$ is the number of collisions per original fast neutron for the $I-t$ group; and $G_{1}, L_{2}$, and $L_{3}$ are the gains and losses, respectively, per collision groups 1,2 , and 3 .

$$
\begin{gathered}
\mathrm{C}_{1}=\frac{\mathrm{f}_{1} \cdot \mathrm{P}\left(\mathrm{a}_{1}, \frac{\mathrm{\kappa R}}{\mathrm{a}_{1}}\right)}{1-\mathrm{P}\left(\mathrm{a}_{1}, 0\right) \cdot \frac{\mathrm{v}_{1} \cdot \mathrm{f}_{1} \cdot \sigma_{\mathrm{f}, 1}+\sigma_{\mathrm{S}, 1,1}}{\sigma_{\mathrm{t}, 1}}} ; \\
\mathrm{C}_{2}=\frac{\mathrm{f}_{2}}{1-\mathrm{P}\left(\mathrm{a}_{2}, 0\right) \cdot \frac{\sigma_{\mathrm{S}, 2,2}}{\sigma_{\mathrm{t}, 2}} \cdot\left[\mathrm{P}\left(\mathrm{a}_{2}, \frac{\mathrm{\kappa R}}{\mathrm{a}_{2}}\right)+\frac{\mathrm{v}_{1} \cdot \sigma_{\mathrm{f}, 1}}{\sigma_{\mathrm{t}, 1}} \cdot \mathrm{C}_{1} \cdot \mathrm{P}\left(\mathrm{a}_{2}, 0\right)\right] ;} \\
C_{3}=\frac{P\left(a_{3}, 0\right)}{1-P\left(a_{3}, 0\right) \cdot \frac{\sigma_{S, 3,3}}{\sigma_{t, 3}}} \cdot \frac{\sigma_{S, 1,3}}{\sigma_{t, 1}} \cdot C_{1} ; G_{1}=\frac{\left(v_{1}-1\right) \cdot \sigma_{f, 1}+\sigma_{c, 1}}{\sigma_{t, 1}} ; \\
L_{2}=\frac{\sigma_{c, 2}}{\sigma_{t, 2}} ; L_{3}=\frac{\sigma_{c, 3}}{\sigma_{t, 3}},
\end{gathered}
$$

Where $v_{l^{-}}$average number of neutrons emitted per $\mathrm{U}^{238}$ fission; $f_{1}$ - fraction of fission neutrons born in group $1 ; f_{2}=1-f_{1}-$ fraction of fission neutrons born in group 2;

$\mathrm{P}\left(\mathrm{a}_{\mathrm{i}}, \frac{\kappa \mathrm{R}}{\mathrm{a}_{\mathrm{i}}}\right)$ - collision probability in fuel for a group I source distributed as the thermal flux;

$k$ - inverse thermal neutron diffusion length, $\mathrm{cm}^{-1 ;} R$ - measure of size of fuel lump, $\mathrm{cm} ; a_{i}=R / \lambda_{i}$, where $\lambda_{i}$ total meanfree path in fuel lump for group $i$ neutrons; $P\left(a_{1}, 0\right)$ - collision probability in fuel for a uniformly distributed source of group i neutrons.

The ratio -is a little less than 1 . In particular, 


$$
\begin{gathered}
\text { при } a=1, \frac{P\left(a_{i}, \frac{\kappa R}{a_{i}}\right)}{P\left(a_{i}, 0\right)} \approx 1-0,012 \cdot \frac{\kappa \cdot R}{a} \\
\text { при } \left.a=0,5, \frac{P\left(a_{i}, \frac{\kappa R}{a_{i}}\right)}{P\left(a_{i}, 0\right)} \approx 1-0,009 \cdot \frac{\kappa \cdot R}{a}\right) \\
\text { при } a \rightarrow 0, \frac{\frac{\kappa \cdot R}{a}<4}{P\left(a_{i}, \frac{\kappa R}{a_{i}}\right)}
\end{gathered}
$$

Fast fission factor is about 1.02 - 1.05 in PWR reactors with tight lattice. This value is caused by neutron scattering by oxygen, since uranium oxide is used as a reactor fuel.

\section{Results}

Results of the calculations are presented in graphics charts.

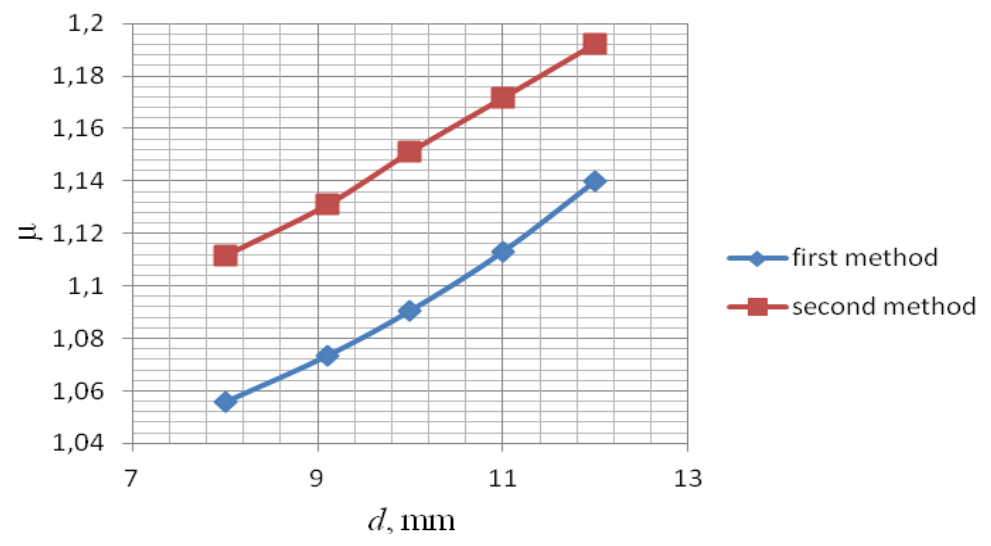

Fig. 3 dependence of the fast fission of the diameter of the block.

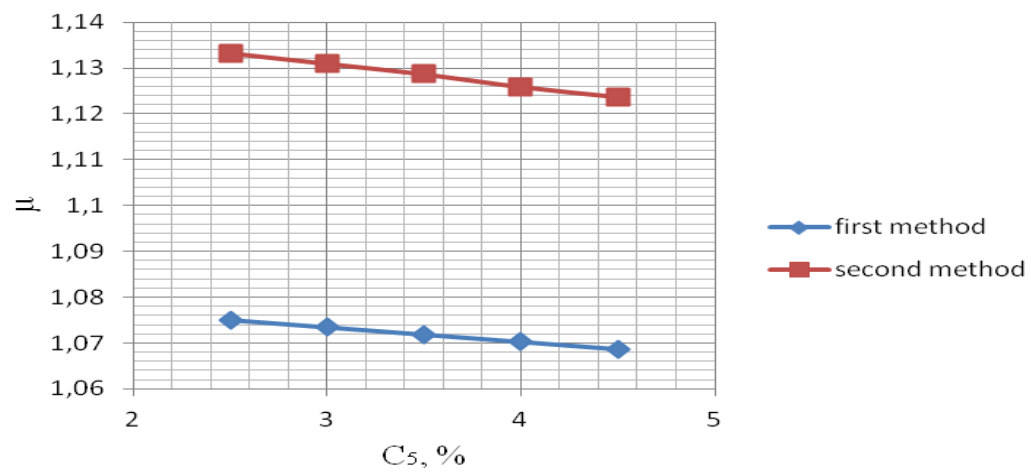

Fig. 4 dependence of the fast fission of ${ }^{235} \mathrm{U}$ fuel enrichment.

\section{Conclusions}

It ought to be remarked that main difficulty in fast fission factor calculation are cross effect and neutron leakage in the high-energy region. These effects has great impact on value of $\mu$, that is why effects reckoning is important for reactors with water-uranium lattice. Presented methods make possible to consider cross effect. Second one considers neutron leakage in consequence of lattice limitation.Computational error is on the average of $6 \%$ in presented methods, so thus it is acceptable to use it in research. 


\section{References}

1. Бартоломей Г.Г., Бать Г.А. и др. Основы теории и методы расчёта ядерных энергетических реакторов: Учебное пособие для вузов - 2-е изд.,перераб. и доп. - М.: Энергоатомиздат, 1989 - 512 с

2. Reactor physics constants. ANL - 5800 Second Edition 1963 year

3. H. Kouts and R. Sher, Experimental Studies of Slightly Enriched Uranium, Water Moderated Lattice, Part I. 0.600-in. Diameter Rods, BNL-486, (September, 1957).

4. Вейнберг А., Вигнер Е. Физическая теория ядерных реакторов. М., Изд-во иностр. лит., 1961.

5. Фейнберг С. М., Шихов С. Б., Троянский В. Б. Теория ядерных реакторов. Т. 1. Элементарная теория реакторов: Учебник для вузов. - М.: Атомиздат, 1978, 400 с.

6. Белл Д., Глесстон С. Теория ядерных реакторов. Перев. С англ. Под ред. В. Н. Артамкина. М., Атомиздат, 1974. с. 496.

7. Глесстон С., Эдлунд М. Основы теории ядерных реакторов. М., Изд-во иностр. лит., 1954.

8. В.А. Кузнецов. Судовые ядерные реакторы (основы теории и эксплуатации): Учебник. - Л.Ж Судостроение, 1988. 264 с. ил. 